Among the exhibits deserving special mention is one of lightning flashes taken during a thunderstorm. Owing to the Clayden effect, a flash occurring at the beginning of the exposure appears as a black line on a grey background, while one occurring at the end of the exposure is white. Some high-speed oscillograms demonstrate that it is now possible to record photographically traces made at a writing speed no less than four per cent of the speed of light. There are also some fine cloud studies and a number of large-scale photographs of geological formations taken from the air.

Some of the exhibits are also reproduced as lantern slides, which provide an interesting comparison with the prints. Unfortunately, they are on different floors. The lantern slides also include some beautiful colour transparencies of crystals in polarized light and of photo-elastic stress patterns of loaded beams and other structures.

The medical photographs are not numerous, which is perhaps just as well for the visitor's peace of mind in view of the extreme degree of clarity achieved in the reproduction of detail.

\section{PHYSICAL CHEMISTRY IN PHARMACY}

$A^{1}$

T the British Pharmaceutical Conference held at Brighton in August, the chairman, Dr. N. Evers, gave an address entitled "The Importance of Physical Chemistry in Pharmacy". He claimed that the importance of this aspect of pharmacy has not been sufficiently appreciated in the past and that the pharmacist requires a wide knowledge of physical and chemical properties of materials. Dr. Evers said the pharmaceutical industry is probably concerned with a wider range of materials than any other, even including the food industry; and that the most important asset which the pharmacist possesses as a result of his training and experience is his familiarity with the properties of materials and his knowledge of their behaviour over a range of different circumstances.

In recent years an ever-widening range of new materials has been offered for the use of the phar. macist by the synthetic chemist; substances which, if used with knowledge and skill, can be made to produce almost any desired properties in the product. In order to make the most effective use of these substances, the pharmacist requires a knowledige of the relevant physical chemistry. It should not be necessary to rely on the manufacturer of such products for suggesting suitable formulæ, because only the user is in a position to know exactly what he requires of his product. It is all the more desirable, therefore, that he should possess the knowledge of physical chemistry which will enable him to produce new preparations by the use of such substances, either for the presentation of new drugs or for new methods of presenting old ones.

\section{Applications of Physical Chemistry}

Without introducing examples which are recondite or unusual, any attempt to make a list of physicochemical phenomena which are encountered by the pharmacist could not fail to include the following items :

\author{
Solubility \\ Iouization \\ Hydrogen ion \\ Mass action and reaction velocity \\ Osmotic pressure \\ Osmotic
Dirtysis \\ Surface tension \\ Emulsification \\ Vapour pressure \\ Dififusion \\ Colloids \\ Adsorption
}

This list does not include the applications of physical chemistry in analytical chemistry, but only phenomena which may be encountered in pharmaceutics.

Large-scale manufacturing pharmacy employs many physico-chemical processes such as evaporation, distillation and drying. The design of plant for such processes involves problems which can safely be left to the chemical engineer; but the pharmacist who uses the products must have a sufficient knowledge of the underlying principles of the processes used to enable him to make a choice of the most suitable method from the point of view of both the effect on the product and of cost. For example, in a new process of drying, such as freeze-drying, there may be no previous experience to guide him, and each problem requires its own solution to be worked out from physico-chemical considerations.

The use of adsorbents in the pharmaceutical industry seems to provide endless problems for research. The purification of active principles by adsorption is not a process which has been much developed. It was used in the carbon adsorption process for penicillin, where incidentally it was found that comparatively few types of carbon were really effective adsorbents. Carbon has been used for the adsorption of pyrogens and 'Permutit' for the removal of traces of adrenalin from cortical extracts. Pussibly the new base-exchange resins may have some uses in this type of work. They have been used, for example, for the conversion of calcium penicillin to sodium penicillin. Chromatographic separation is not particularly suitable for large-scale work, and probably has its chief uses in the research laboratory and in the purification of highly active substances which are only produced in small quantities.

The sterile filtration of injections bristles with physico-chemical problems mainly connected with the adsorption of active principles by the filtering medium. Even sintered glass is not entirely guiltless in this respect, and there are instances where no method of sterile filtration can be used without loss of potency. There seems no doubt that in some cases the filtering medium exerts a chromatographic effect, and that an initial adsorption may occur which is afterwards washed out.

\section{Rheology}

The science of rheology is defined by its chief exponent, Dr. G. W. Scott Blair, as concerned with the "deformation and flow of matter". The two lectures given by Dr. Scott Blair recently to the Pharmaceutical Society gave an indication of the scope of rheology and its importance in pharmacy. It is concerned with the properties of solids and liquids such as viscosity, surface tension, thixotropy, elasticity, hardness or softness, and those vague attributes which we know as 'consistency', 'firmness', 'springiness', 'toughness', 'tackiness', 'body' and other such terms. Many of these properties are not measurable in a quantitative manner, and the human 
thumb is the most valuable piece of apparatus avail. able for assessing them. The formulation of a product of the desired rheological properties is therefore largely a matter of experience. Nevertheless, these vague rheological properties are produced by a combination of well-known physical properties, and a man with a knowledge of the physical chemistry involved is definitely at an advantage.

Physical chemistry is not easy to make attractive. It is not so teachable as organic chemistry. It requires a knowledge of mathematics, which is repugnant to many minds, or, because of a lack of early training in mathematics, the student cannot appreciate what he is taught. Is the lack of interest in physical chemistry due to the fact that pharmaceutical students do not appreciate its importance in their work? Are the courses often merely general courses in the subject, in which no attempt is made to adapt them for pharmaceutical students or to bring home the applications of what they are taught to the practice of pharmacy? Presumably the text. books used are well-known general text-books on the subject, in which pharmaceutical applications are not considered. Surely what is needed is for some genius to arise who will produce a classical text-book of physical chemistry for pharmaceutical students. No student should be taught applied physical chemistry before he learns the fundamentals of the subject, but physical chemistry should be taught to students of pharmacy in the same way as organic chemistry is taught, with a bias towards medicinal compounds.

\section{ARTIFICIAL HUMAN INSEMINATION*}

$\mathrm{T}$ HIS is a disappointing document. The Commission was asked "to consider the practice of human artificial insemination with special reference to its theological, moral, social, psychological and legal implications". But the Archbishop in his preface states that it is not to be taken as a "Church document", though he does not explain what exactly such a document is.

The two sections on the psychological and socio. logical aspects of the problem are admittedly based upon surmise, for there is no evidence on the subject available either in Great Britain or the United States, and for this reason it might have been well to omit them altogether; as it is, very little weight can be attached to them.

The real importance of the report lies in two sections : one on the legal aspects, and the other on the theological principles. Both are able and clear, and obviously much thought has been given to them. It is, however, surprising that the religious statement comes at the end. One would have expected it at the beginning, where it should have constituted the major part of the report. For it is in this section that the Christian will look for an authoritative statement and for guidance, and it is here that a Committee appointed by the Archbishop of Canterbury is best qualified to speak. It will no doubt be accepted as the Church's view on the subject for many years to come, and for this reason alone could well have been expanded. Here the question arises: Why does the Archbishop state that it is not to be considered as a "Church document"? Would it not have been * A Report of a Commission appointed by His Grace the Archbishop
of Canterbury. (S.P.C.K.) 28. 6 d. net. better if this section of the report, at any rate, had been drafted in such a way that it could have been taken as such ? If there had been any chance of the Church as a whole not accepting it, or of its altering its views, then it would certainly have been better for the report not to have made the definite recom. mendation that steps should be taken "to frame legislation to make the practice [of artificial in. semination-donor] a criminal offence" but to have withheld judgment on this point for a little longer. It does not seem possible to have it both ways, for when a committee appointed by the Archbishop advises that a certain practice be made a criminal offence, then such a recommendation, to carry weight, should bear with it the full authority of the Chair of St. Augustine.

The lawyers have produced much the most vigorous section in the report, condemning artificial insemination from the donor as adultery, and from them comes the first suggestion that it be made a criminal offence. They admit, however, that the questions which the practice raises have not yet come before the English courts, and so far as English law is concerned they are only able to quote a speech of Lord Dunedin in the House of Lords, concerning Russell $v$. Russell, 1924: "and fecundation ab extra is, I doubt not, adultery__ "They quote, however, a Canadian case, Orford $v$. Orford, which occurred as far back as 1924, and in which a wife alleged that she had been artificially inseminated without her husband's knowledge ; but they omit to mention that no practitioner either here or in Canada or the United States would countenance such procedure, the consent of both partners being a fundamental requirement.

Since the publication of the report there has, however, been a case in the Supreme Court of New York State which has a direct bearing on the problem. In it the judge, Mr. Justice Greenberg, was asked to declare that a child whose mother had been artificially inseminated with the husband's consent was illegitimate. This he refused to do, saying that it would be "inhuman, inhumane and contrary to the highest concepts of sociology $y^{1}$. Further, he declared the child to be legitimate and the husband to be the legal father."

The question of the artificial insemination of unmarried women is raised, but it is very difficult to believe that the Commission had any evidence that it has been practised in Britain, for all responsible opinion is against it. Another point that might in fairness have been stated clearly is that the child of a married woman is presumed to be legitimate unless proved to be otherwise; a very difficult proof to produce, and the lack of which would make it impossible to enforce any law against donor insemination, when it has been performed with the husband's consent, unless, of course, the medical practitioner who performed the insemination himself gave information, thereby laying himself open, as the lawyers suggest, to a charge of criminal conspiracy, which is indeed unlikely to happen. This again raises the question whether such law would have the backing necessary from the public to make it effective.

The legal section is in strong contrast with the rest of the report, where obvious efforts have been made to keep a balanced and charitable judgment. This is a pity, because unless the practice is made illegal-and it is very doubtful if this will be doneartificial insemination is likely to continue on the 